
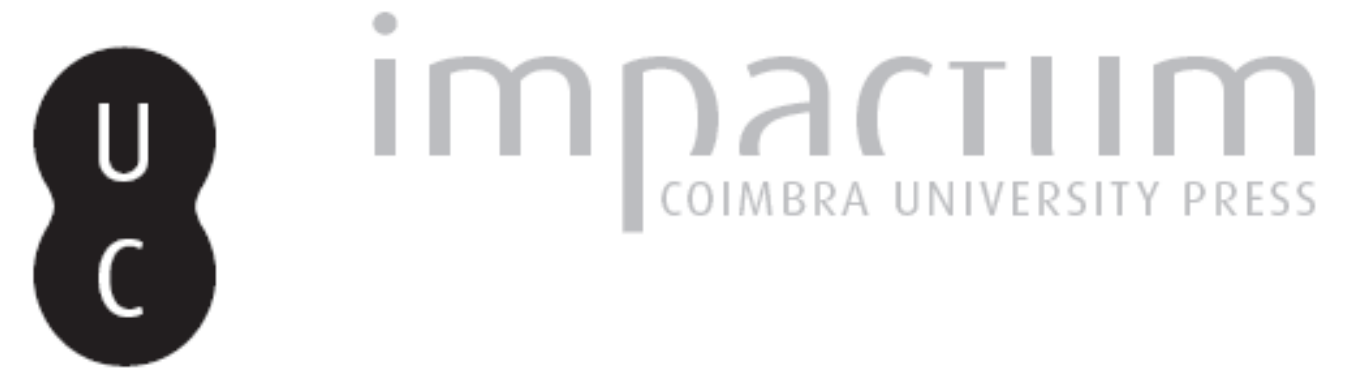

\title{
Fichas de registo de dano pós-sismo
}

Autor(es): $\quad$ Santos, Ruben; Vicente, Romeu da Silva

Publicado por: Associação Portuguesa de Riscos, Prevenção e Segurança

URL persistente:

URI:http://hdl.handle.net/10316.2/35845

DOI:

DOI:http://dx.doi.org/10.14195/1647-7723_20_12

Accessed : $\quad$ 26-Apr-2023 10:44:52

A navegação consulta e descarregamento dos títulos inseridos nas Bibliotecas Digitais UC Digitalis, UC Pombalina e UC Impactum, pressupõem a aceitação plena e sem reservas dos Termos e Condições de Uso destas Bibliotecas Digitais, disponíveis em https://digitalis.uc.pt/pt-pt/termos.

Conforme exposto nos referidos Termos e Condições de Uso, o descarregamento de títulos de acesso restrito requer uma licença válida de autorização devendo o utilizador aceder ao(s) documento(s) a partir de um endereço de IP da instituição detentora da supramencionada licença.

Ao utilizador é apenas permitido o descarregamento para uso pessoal, pelo que o emprego do(s) título(s) descarregado(s) para outro fim, designadamente comercial, carece de autorização do respetivo autor ou editor da obra.

Na medida em que todas as obras da UC Digitalis se encontram protegidas pelo Código do Direito de Autor e Direitos Conexos e demais legislação aplicável, toda a cópia, parcial ou total, deste documento, nos casos em que é legalmente admitida, deverá conter ou fazer-se acompanhar por este aviso.

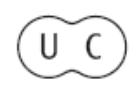




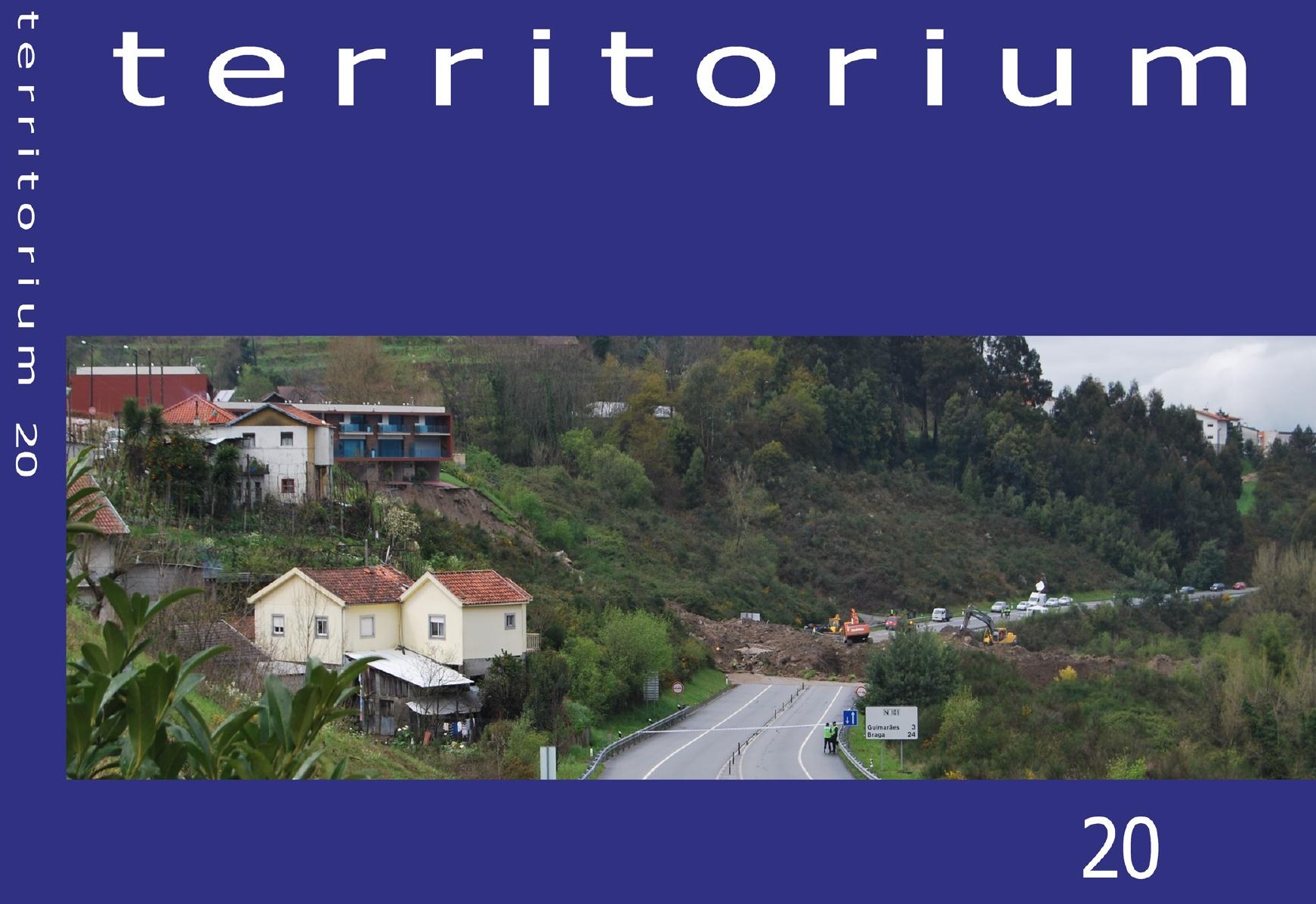

Riscos, População e Segurança 
Ruben Santos

Departamento de Engenharia Civil da Universidade de Aveiro rubensantos@ua.pt

Romeu da Silva Vicente

Departamento de Engenharia Civil da Universidade de Aveiro romvic@ua.pt

\section{RESUMO}

As catástrofes naturais são fenómenos de grande impacto, impossíveis de evitar. Cabe a nós seres humanos e habitantes desta "pequena" esfera fazer tudo o que está ao nosso alcance para minimizar as suas consequências, tanto no que concerne a vítimas humanas, como às perdas económicas e materiais. Com o avanço da tecnologia, é possível nos dias de hoje, prever a ocorrência de um fenómeno deste tipo em escassos segundos, evitando uma catástrofe de maior envergadura. 0 desenvolvimento de ferramentas de alerta tornou-se uma ajuda importante na previsão da ocorrência de sismos.

Palavras-chave: Catástrofes naturais; dano sísmico; registo de dano pós-sismo.

\section{RESUMEN}

Formularios de inscripción de daños después del terremoto - Los desastres naturales son eventos de gran impacto, imposibles de evitar. Depende de nosotros los seres humanos y habitantes de esta "pequeña" bola de hacer todo lo que esté a nuestro alcance para reducir al mínimo sus consecuencias, tanto en lo que respecta a las víctimas humanas, como las pérdidas económicas y materiales. Con el avance en la tecnología de hoy es posible predecir la aparición de un fenómeno de este tipo en unos pocos segundos, evitando una catástrofe a mayor escala. El desarrollo de herramientas de alerta se ha convertido en una importante ayuda en la predicción de terremotos.

Palabras clave: Desastres naturales, daños del terremoto, registro de los daños tras el terremoto.

\section{RÉSUMÉ}

Formulaire d'inscription de post-tremblement de terre des dommages - Les catastrophes naturelles sont des événements de grand impact, impossibles à éviter. C'est à nous les humains et les habitants de cette "petite" boule tout faire en notre pouvoir pour minimiser leurs conséquences, tant en ce qui concerne les victimes de l'homme, que les pertes économiques et matérielles. Avec l'avancement de la technologie, il est aujourd'hui possible de prédire l'apparition d'un phénomène de ce type en quelques secondes, évitant une catastrophe à grande échelle. Le développement d'outils d'alerte est devenue un outil important dans la prédiction des tremblements de terre.

Mots-clé: Catastrophes naturelles, dégâts tremblement de terre, l'enregistrement de l'après-tremblement de terre.

\section{ABSTRACT}

Post-seismic damage registration - Natural disasters are events of great impact, impossible to avoid. It's up to us humans and inhabitants of this "small" ball do everything in our power to minimize their consequences, both with regard to human victims, as the economic and material losses. With the advancement in technology it is possible today to predict the appearance of a phenomenon of this type in a few seconds, avoiding a catastrophe on a larger scale. The development of warning tools has become an important aid in the prediction of earthquakes.

Keywords: Natural disasters, earthquake damage, registration of post-earthquake damage.

\footnotetext{
* O texto deste artigo corresponde à comunicação apresentada ao VII Encontro Nacional de Riscos e I Forum ISCIA, tendo sido submetido para revisão em 28-09-2012, e aceite para publicação em 12-11-2012.

Este artigo é parte integrante da Revista Territorium, n. ${ }^{\circ} 20,2013,{ }^{\circ}$ RIscos, ISBN: 0872- 8941.
} 


\section{Introdução}

$\mathrm{Na}$ actualidade, mais de metade da população mundial vive em centros urbanos localizados nas grandes cidades. Estas cidades são consideradas como o cordão umbilical da sociedade, uma vez que tudo se desenvolve em torno delas. Actuam como motor económico, são o centro tecnológico de inovação e nelas estão localizados inúmeros edifícios do nosso património cultural. Por outro lado, também têm as suas desvantagens, como a possibilidade da queda de infra-estruturas, a degradação do ambiente urbano e a existência de milhões de pessoas que vivem em bairros marginais em todo o Mundo. Todos estes factores contribuem para o incremento da vulnerabilidade de muitas cidades mesmo antes das ameaças naturais.

Estima-se que num futuro próximo, mais de metade da população mundial viva junto de cidades, uma mudança enorme desde os tempos em que a maioria das pessoas vivia em quintas ou perto delas. A vida urbana tem um impacte muito grande sobre o mundo natural, pois tudo o que as pessoas necessitam tem de ser trazido de fora das cidades (D. BurNiE, 2004). Cidades como São Paulo (Brasil), Bombaim (Índia) e Tóquio (Japão), que ocupam centenas de quilómetros quadrados de terra, encontram-se no topo das super cidades, nas quais o número de habitantes cresce aos milhares diariamente, (fig.1).

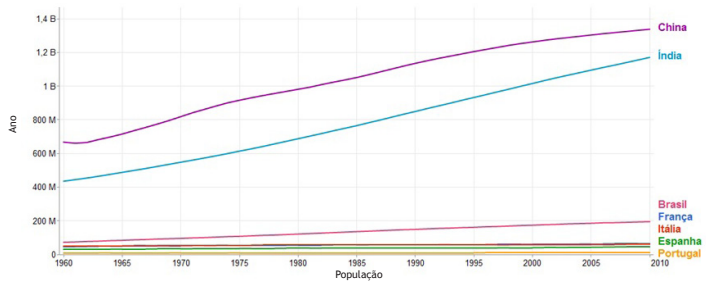

Fig. 1 - Evolução do número de habitantes em diversos países desde 1960 até 2011. Fonte: BANCO MUNDIAL, 2011.

Olhando para todas estas causas e tomando consciência que temos de saber viver com os desastres naturais, impossíveis de evitar, cabe a nós seres humanos fazer o possível para minimizar as suas consequências.

Apesar do país onde vivemos, Portugal, não ser tão fustigado como outros países em termos de acidentes naturais de grande envergadura, temos de estar também preparados e em permanente estado de alerta para a eventualidade deles acontecerem. Facilmente recordamos o terramoto de 1755 que devastou toda a baixa Lisboeta. Desde então, houve uma evolução de ordem tecnológica que não foi acompanhada em termos práticos.

Há milhões de anos que somos constantemente fustigados com acidentes naturais. Estes fazem-se sentir por todo o Mundo, não escolhem a hora, muito menos a cidade onde vão eclodir. Desde então, têm sido enveredados esforços quer a nível local quer a nível global, para fazer face a estes gigantescos imprevistos. O principal objectivo antes da ocorrência destes acidentes, é o facto de se estar preparado para eles, o que na maior parte das vezes não acontece, apanhando assim a população e as entidades intervenientes de surpresa.

\section{Riscos Geológicos}

Há milhões de anos que somos constantemente fustigados com acidentes naturais. Estes fazem-se sentir por todo o Mundo, não escolhem a hora, muito menos a cidade onde vão eclodir. Desde então, têm sido enveredados esforços quer a nível local quer a nível global, para fazer face a estes gigantescos imprevistos. O principal objectivo antes da ocorrência destes acidentes, é o facto de se estar preparado para eles, o que na maior parte das vezes não acontece, apanhando assim a população e as entidades intervenientes de surpresa.

O impacte dos riscos geológicos nas nossas vidas e na economia é enorme e nunca deixará de existir. Inundações, tsunamis, tempestades, seca, incêndios, erupções vulcânicas, sismos, deslizamentos e abatimentos de terra, (fig.2), são responsáveis, todos os anos, pela perda de milhares de vidas, originando idêntico número de feridos e destruindo lares e meios de subsistência (T. BeER et al, 2007).

O crescente aumento da população Mundial, a política de crescimento selvagem e a complexidade das organizações sociais, entre outros, são factores que podem explicar estes acontecimentos inesperados. 0 uso não sustentável do território e as técnicas de construção incorrectas, especialmente em países em desenvolvimento, são causas do elevado dano na sequência de um evento
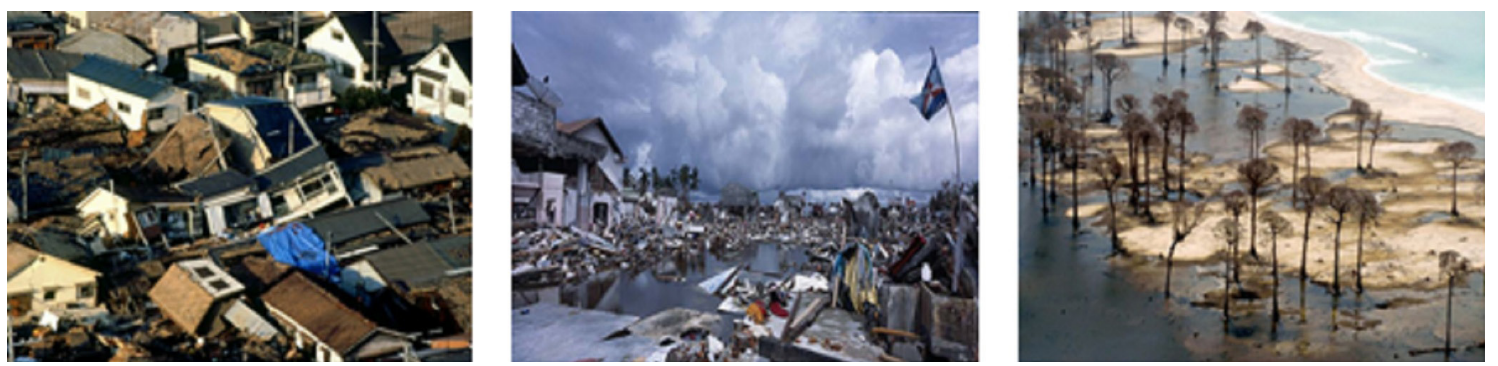

Fig. 2 - Cenários visíveis após desastres naturais. Fonte: L. ABASSI, 2010. 
sísmico. Conclui-se, que a sociedade se tornou mais vulnerável à medida que o desenvolvimento evoluiu.

Seguidamente (TABELA I) apresenta-se um quadro representativo dos sismos a nível mundial mais devastadores ocorridos desde o ano de 1905, adaptado de (C. Oliveira, 2008) e (C. Scawthorn, 2003).

TABela I - Historial de sismos mais devastadores a Nível Mundial, desde 1905 até 2011.

\begin{tabular}{|c|c|c|c|}
\hline Ano & Regiões & $\begin{array}{l}\text { Vitimas } \\
\text { mortais }\end{array}$ & Mw \\
\hline 1905 & India & 19000 & 8.6 \\
\hline 1906 & Chile & 20000 & 8.6 \\
\hline 1907 & Asia Central & 12000 & 8.1 \\
\hline 1920 & China & 220000 & 8.5 \\
\hline 1920 & Japão & 143000 & 7.9 \\
\hline 1923 & China & 80000 & 8.0 \\
\hline 1935 & Chile & 28000 & 8.3 \\
\hline 1939 & Turquia & 33000 & 8.0 \\
\hline 1970 & Perú & 67000 & 7.7 \\
\hline 1976 & Guatemala & 23000 & 7.5 \\
\hline 1976 & China & 242000 & 7.8 \\
\hline 1985 & México & 10000 & 8.1 \\
\hline 1990 & Manjil, Irão & 40000 & 7.7 \\
\hline 1999 & Izmit, Turquia & 30000 & 7.4 \\
\hline 2001 & Gujará, India & 20000 & 7.7 \\
\hline 2004 & NW Sumatra & 300000 & 9.2 \\
\hline 2008 & Sichuan, China & 88000 & 7.8 \\
\hline 2010 & Port-au-Prince, Haiti & 222570 & 7.0 \\
\hline 2010 & Concepcion, CHile & 1000 & 8.8 \\
\hline 2011 & Sendai, Japão & 28050 & 8.9 \\
\hline
\end{tabular}

Fonte: Adaptado de C. Oliveira, 2008 e C. SCAWTHORn, 2003.

Através da observação da TABELA I, podemos verificar a violência dos fenómenos sísmicos que se têm sentido um pouco por todo o Mundo, criando um cenário de destruição e elevadas perdas, (fig.3), quer a nível humano quer a nível financeiro. Podemos considerar o sismo ocorrido a Dezembro de 2004, em Padang Sumatra, como o mais destrutivo dos últimos 100 anos, com magnitude local 9,2 , fazendo cerca de 300 mil vítimas mortais. Segundo consta, foi um dos mais potentes sismos de todos os tempos, registados mundialmente e, um dos que teve consequências mais trágicas também.

\section{Risco Sísmico}

Para fazer frente ao risco natural, há que apostar mais em políticas de "protecção", de preparação das populações, para atenuar e minimizar as consequências das catástrofes inerentes aos caprichos da Terra. Os sismos têm de ser combatidos como um esforço comum entre científicos, engenheiros, sismólogos, peritos em telecomunicações, matemáticos, urbanistas, entre outros. Só desta forma é possível quantificar e reduzir o risco (R. CLAESSEns, 2008).

Portanto quando falamos acerca dos perigos Naturais, estamos a referir-nos aos eventos que são desencadeados ou relacionados com fenómenos da natureza. Os acidentes causados pelo Homem dominam o panorama acerca do número de mortes em todo o Mundo (C. Oliveira et al, 2006).

Um dos problemas dos sismos é o facto de em poucos segundos poderem ser afectadas grandes áreas do território. Por exemplo, por causa das vibrações ou das ondas do tsunami, podem chegar a grandes distâncias ainda com potencial de destruição. Isto faz com que o fenómeno sísmico seja bastante diferente dos outros fenómenos naturais ou tecnológicos que se sentem em zonas localizadas ou que se dão de uma forma espaçada ao longo do tempo (C. Oliveira et al, 2008).

Apesar dos sismos serem um fenómeno natural inevitável e incontrolável, os seus efeitos não o são. Desta forma, é possível evitar que os sismos dêem lugar a grandes catástrofes (J. Azevedo, 2008) Portanto, num sismo encontram-se diversos elementos que, actuando em conjunto, provocam impactes acrescidos, nomeadamente vibrações, incêndios, rotura de sistemas implantados para socorro, tsunamis, entre outros. 0 impacte dos sismos é muito diversificado, com efeitos directos sobre a população, as construções e as infraestruturas e efeitos indirectos sobre o turismo e a economia em geral. A população acaba também por sofrer alguns efeitos indirectos, nomeadamente sobre a forma de pensar e as atitudes pessoais, que poderão influenciar a cultura, a religião, a filosofia e a política (C. Oliveira et al, 2008).

O risco sísmico é um conceito que tem várias definições consoante o seu autor. Representa as perdas que um dado
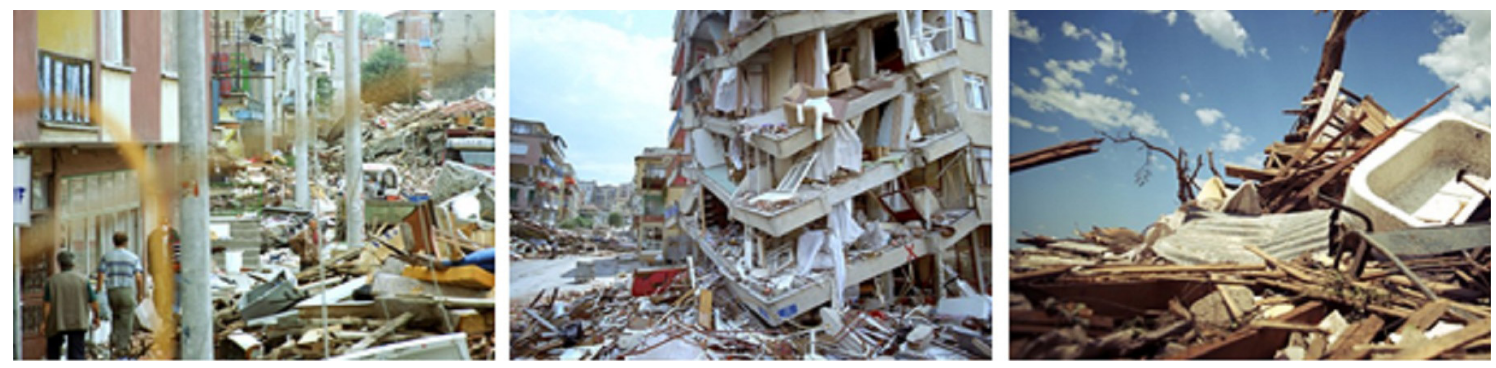

Fig. 3 - Cenários de destruição. Fonte: M. KoвAYSHI,2004. 
elemento exposto sofrerá, como resultado de sismos futuros e a probabilidade das mesmas ocorrerem para um certo período de tempo de exposição. O elemento em risco poderá ser um edifício, uma cidade, um país, a população que neles habita, um sistema de infra-estruturas ou uma dada actividade económica (E. CANSADO, 2001).

O risco sísmico pode ser entendido como uma medida do potencial de perda, como nível de destruição ou dano, em consequência da ocorrência de um determinado evento sísmico (R. VICENTE et al, 2010).

\section{Factores}

Podemos afirmar que o risco sísmico é condicionado por três factores: a vulnerabilidade, a perigosidade e a exposição, (fig.4). Podemos considerar que a vulnerabilidade é definida como o grau de perda para um determinado elemento em risco, ou um conjunto de elementos, resultantes da ocorrência de um perigo (M. ERDIK, 1996). A vulnerabilidade é pelo contrário, um factor que resulta da acção do Homem e sobre o qual se pode actuar com facilidade em muitos casos.

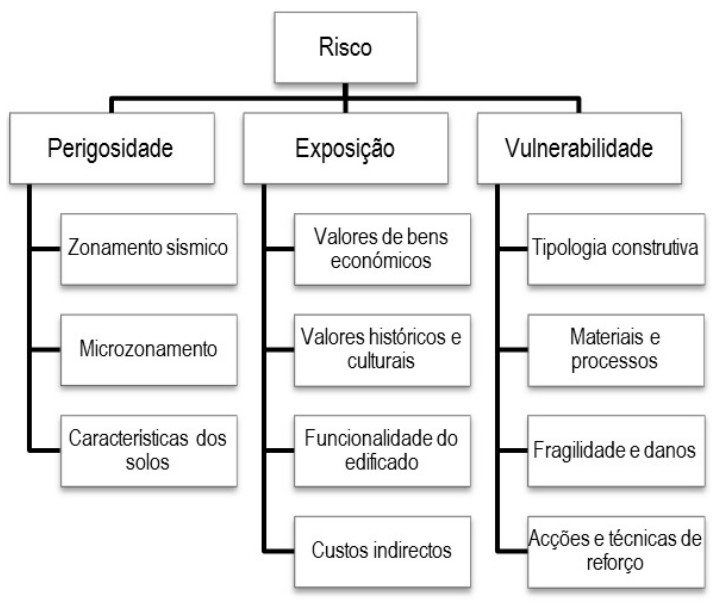

Fig. 4 - Factores de que depende o risco sísmico. Fonte: Adaptado de R. VICENTE, 2008.

Com o desenvolvimento tecnológico de hoje em dia já é possível, à engenharia civil, projectar e construir edifícios, pontes, túneis e outras construções e infraestruturas, com capacidade de resistir a sismos de magnitude elevada (C. Oliveira et al, 2008). Em geral, não é possível ao Homem, reduzir a perigosidade sísmica pois é um fenómeno natural fora do seu controle. A perigosidade sísmica é entendida como a probabilidade de ocorrência de um fenómeno com uma determinada magnitude num determinado período de tempo e numa dada área (J. ZÊZERE et al, 2007).

A capacidade de actuar sobre a exposição em grande escala, é também muito reduzida, pois implicaria restringir a fixação das populações em zonas de maior risco sísmico, sendo que estas representam um terço da população do planeta. No entanto, a uma escala muito menor é possível reduzir a exposição, no caso de encostas com grande potencial de deslizamento ou terrenos com forte potencial de liquefacção, uma vez que as áreas envolvidas são muito menores. Ainda assim, como a grande parte dos casos de acidente se deve a vibrações do solo, que não poupam zona nenhuma do interior da região afectada, conclui-se que não é possível agir sobre a principal causa dos danos provocados pelos sismos (C. OliveIRa et al, 2008).

\section{Gestão do Risco Sísmico}

Desde muito cedo, prever um fenómeno natural, em particular os sismos, foi o grande objectivo da humanidade. Dada a complexidade dos processos de rotura na origem dos sismos não permite à ciência produzir previsões de sismos num prazo razoável que satisfaça as necessidades, tais como: saber o tempo, localização e dimensão do próximo evento (C. OLIvEIRA et al, 2006). Mesmo que haja uma previsão hipotética de pequeno valor (dias ou semanas), para outras regiões seguras, relativamente às perdas económicas não há nada a fazer, mas o mais importante é evitar perdas humanas. Recentemente, com o desenvolvimento da rapidez de transmissão e tratamento de dados, é possível projectar sistemas de alerta prévio, que após a ocorrência de um sismo, fornecem informação acerca da possibilidade da ocorrência de réplicas (C. Oliveira et al, 2006). Por outro lado, uma previsão de médio e longo prazo (cerca de 100 anos), é usada frequentemente para avaliar o risco sísmico, quer a nível regional ou local, e avaliar as zonas mais expostas e qualificar as possíveis acções sísmicas.

Uma adequada estratégia de prevenção deve incluir três princípios, sendo eles, (C. Oliveira et al, 2006):

- Reconhecimento do fenómeno sísmico e as suas consequências no ambiente construído;

- Avaliação do risco nos perigos sísmicos e vulnerabilidades sísmica de todos os componentes do ambiente construído;

- Consciência da importância dessas avaliações e colocar em prática acções diferentes a fim de mitigar os riscos estimados.

A par da importância da fase de mitigação e redução do risco de desastres naturais, também a fase posterior à ocorrência de um sismo é importante. O que acontece após a ocorrência de um sismo é uma consideração que devemos ter sempre em mente, as entidades competentes devem ter sempre um plano de resposta em caso de emergência.

A dinâmica do ciclo das catástrofes deve ser reflectida no planeamento da emergência, (fig.5). O plano de emergência, ferramenta essencial em caso de acidente grave, catástrofe ou calamidade, tem como principal 
objectivo a implementação de medidas preventivas com a finalidade de gestão, em situações de emergência e de retomar a normalidade (ALEXANDER, 2002).

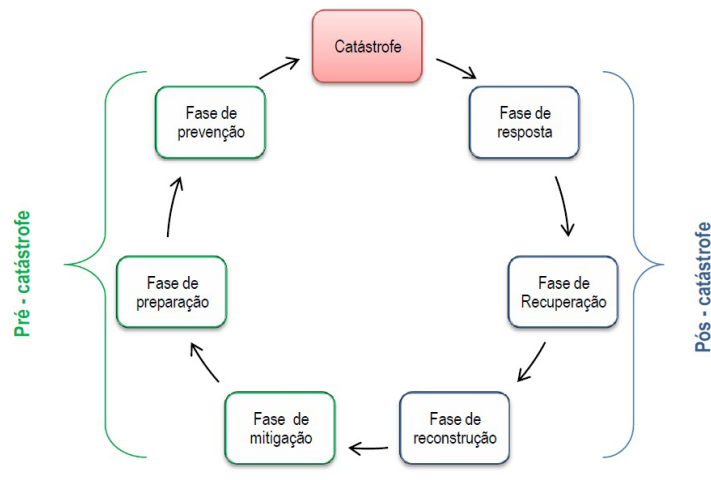

Fig. 5 - Ciclo de gestão de catástrofes.

Fonte: Adaptado de D. Alexander, 2002.

A gestão de risco é um processo que engloba uma série de acções que apoiam a implementação de medidas que reduzam o potencial de perda na ocorrência de um evento, por exemplo, sísmico. Um dos mais vulgares produtos finais na implementação de um programa de gestão de risco é a definição de um plano de emergência. Porém, a avaliação do risco sísmico é apenas uma das tarefas, da teia complexa da gestão de risco de um sistema urbano (R. VICENTE et al, 2010).

\section{Fichas de Registo Pós-sismo}

No que diz respeito à organização das actividades a executar pós-sismo, com o mesmo fundamento, evitar danos maiores, estas são destinadas a avaliar os efeitos dos danos a objectos, ambientes e redes, e contribuir para a activação das medidas de redução dos efeitos. As actividades de verificação de utilização dos edifícios desempenham um papel particularmente importante nesta fase, a par com a necessidade de hospitalização da população e da ajuda que as pessoas afectadas precisam. Mesmo em sismos de baixa-média magnitude pode chegar a milhares de edifícios inspeccionados, por isso é vital fornecer um procedimento específico de organização e gestão de toda a operação (C. BAGGIO et al, 2000).

Há desta forma uma necessidade em reduzir ao máximo as perdas, quer através da formulação de estratégias, sistemas de gestão de emergência, criação de cenários de eventos sísmicos, entre outros.

O desenvolvimento de fichas de levantamento de dano pós-sismo tem como objectivo a execução do levantamento das características tipológicas, de dano e da operacionalidade de edifícios sujeitos a acontecimentos sísmicos. É, desta forma, possível avaliar de uma forma rápida o estado dos edifícios, estimando assim um custo para o seu melhoramento e/ou reparação. Estas fichas são destinadas a edifícios correntes, geralmente em alvenaria, excluindo-se desta forma edifícios integralmente de betão armado ou edifícios de estrutura metálica. Por outro lado, estas fichas foram executadas para edifícios destinados a habitação ou outros serviços, sendo outra tipologia de edifícios, caso de igrejas, teatros, etc, alvo de outro modelo de fichas próprio para essas tipologias.

Podemos considerar dois modelos diferentes de fichas, a ficha de levantamento expedito que é utilizada para situações menos gravosas, em que não seja necessário recorrer a uma inspecção mais detalhada e a ficha de levantamento detalhado para situações mais gravosas. Por sua vez a escala utilizada na quantificação de dano nos elementos existentes, em ambos os modelos, é a EMS 98 (TABELA II).

TABELA II - Classificação utilizada na avaliação de dano.

\begin{tabular}{|c|c|c|}
\hline Sem dano & 00000 & Sem qualquer tipo de dano \\
\hline $\begin{array}{l}\text { Dano } \\
\text { ligeiro }\end{array}$ & - 0000 & $\begin{array}{l}\text { E um dano que não coloca em } \\
\text { causa a resistência global ou local } \\
\text { da estrutura e não afecta } \\
\text { segurança dos ocupantes por causa } \\
\text { da queda de elementos }\end{array}$ \\
\hline $\begin{array}{c}\text { Dano } \\
\text { moderado }\end{array}$ & $\bullet \bullet ০ ০ ০$ & $\begin{array}{l}\text { É um dano em que é necessário ter } \\
\text { precauções }\end{array}$ \\
\hline $\begin{array}{l}\text { Dano } \\
\text { grave }\end{array}$ & $\bullet \bullet \bullet \bigcirc \bigcirc$ & $\begin{array}{l}\dot{E} \text { um dano que coloca em causa a } \\
\text { resistência global ou local da } \\
\text { estrutura e afecta a segurança dos } \\
\text { ocupantes devido a queda de } \\
\text { elementos }\end{array}$ \\
\hline $\begin{array}{l}\text { Dano } \\
\text { muito } \\
\text { grave }\end{array}$ & $\bullet \bullet \bullet \bullet \bigcirc$ & $\begin{array}{l}\text { É um estado em que o edifício já } \\
\text { possui elevado grau de dano, em } \\
\text { que a resistência do edifício se } \\
\text { aproxima do limite, podendo } \\
\text { colapsar parcial ou totalmente. }\end{array}$ \\
\hline Colapso & $\bullet \bullet \bullet \bullet \bullet$ & O edifício colapsou \\
\hline
\end{tabular}

Fonte: Adaptado de EMS 98.

Com esta classificação, é possível uniformizar todo o processo de levantamento de dano, tornando mais fácil a sua avaliação.

Relativamente à ficha de Levantamento Expedito - Modelo A, (fig.6), esta teve por base a "Scheda di $1^{\circ}$ Livello di Rilevamento danno, pronto intervento e agibilità per edifici ordinari nell'emergenza post-sismica", tendo sofrido algumas alterações (AEDES 2000).

Esta ficha de $1^{\circ}$ nível é composta por 4 secções. A primeira secção A "Detalhes do edifício", destinada ao levantamento dos detalhes do edifício, assim como a identificação, descrição, tipologia do edifício. $\mathrm{Na}$ segunda secção B "Danos nos elementos do edifício", é possível quantificar os danos nos diversos elementos do edifício, elementos estruturais e não estruturais, avaliando de forma geral o risco a que o edifício está sujeito. Na terceira secção C "Medidas de emergência de rápida realização”, são descritos os procedimentos a executar após a ocorrência do evento, especificando se as medidas são localizadas ou de extensas, e estimando um valor de custo. Por fim na secção D “Outros 


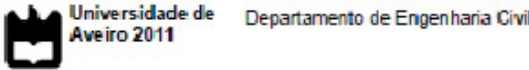

Ficha de Levantamento Expedito de Dano em edficios comentes - Modelo A

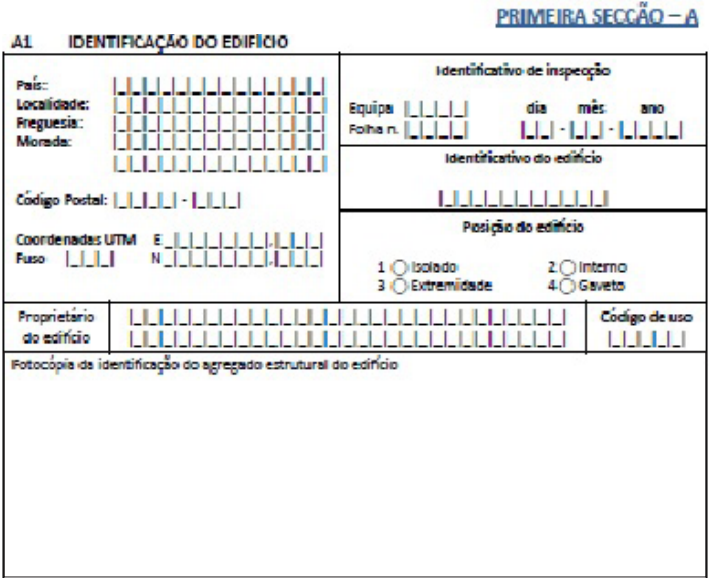

Fig. 6 - Aspecto da ficha de Levantamento Expedito de Dano em edifícios correntes - Modelo A.

SEGUNDA SECCÃO-B

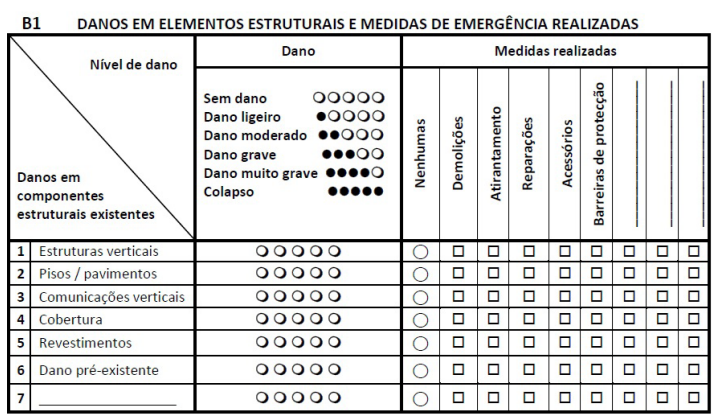

Fig. 7 - Exemplo da segunda secção do Modelo A.

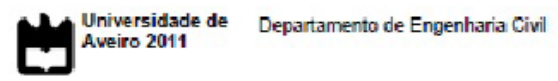

Ficha de Levartamento Detalhado de Dano em exificios comentes - Modelo B PRIMEIRASEOCÃ̃O-A

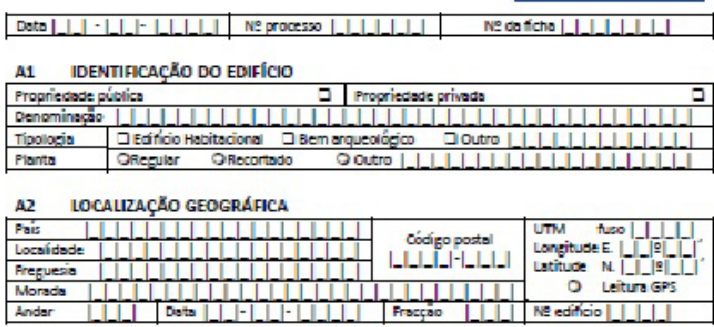
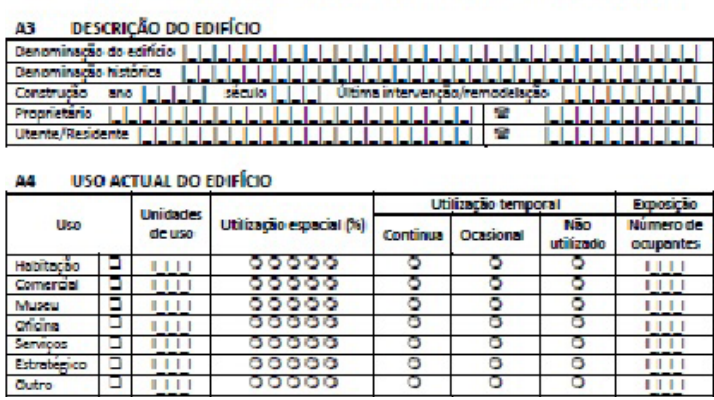

Fig. 8 - Aspecto da ficha de Levantamento Detalhado de Dano em edifícios correntes - Modelo $B$. pormenores importantes", destina-se para descrever todos os detalhes que se mostrem importantes no decorrer do levantamento e para posterior resolução do problema. A título de exemplo é apresentado de seguida, (fig. 7), um campo da segunda secção, onde é feita a correspondência entre os componentes estruturais existentes e o dano presente nos mesmos, e com as devidas medidas de emergência a serem tomadas.

Por outro lado e para situações que necessitem de uma inspecção mais exaustiva temos a ficha de Levantamento Detalhado - Modelo B, (fig.8). A base da compilação desta ficha foi a "Scheda per il rilievo del danno ai Beni Culturali - Palazzi, modelo B - DP”, de Emergenza postsisma, do Departamento de Protecção Civil de Itália, tendo no entanto sofrido algumas alterações (PC 2006).

Esta ficha encontra-se dividida em 4 secções de A a D, havendo em cada secção uma série de pontos, sendo eles: Secção A (A1-A11) - Descrição do edifício; Secção B (B1B9) - Estado do Edifício; Secção C (C1-C7) - Mecanismos de Colapso e por fim Secção D (D1-D5) - Reparações e custos. Em seguida segue a estrutura detalhada das 4 secções, (fig. 9). Todos os campos de preenchimento neste Modelo $B$ são bastante pormenorizados, tornando este modelo muito mais completo que o Modelo A, apresentado anteriormente.

\begin{tabular}{|c|c|c|c|}
\hline A & Descrição do edficio (A1-A11) & $B$ & Estado do edficicio (B1-B9) \\
\hline A1 & Identificaçăo do edficio & $B 1$ & Estado de manutenção geral \\
\hline A2 & Localização geográfica & B2 & Acosoes de intervençăo efectuadas \\
\hline$A^{3}$ & Descrição do edficio & B3 & Regulandade, forma em planta e dados \\
\hline A4 & Uso actual do edificio & \multicolumn{2}{|c|}{ dimensionais } \\
\hline A5 & Caracteristicas morfológicas & 84 & Subdivisăo em elemertos \\
\hline A6 & Contexto urbano e localzação & B5 & Esquematzzação da planimetria do edficio \\
\hline A7 & Infra-estruturas & $B 6$ & Levantamento de dano em elementos estruturais \\
\hline$A 8$ & Presença de riscos & & Levantamento de dano em elementos não \\
\hline A9 & Tipologia do bem artistico presente & \multicolumn{2}{|c|}{ estruturais } \\
\hline A10 & Documentação fotográfica & $B 8$ & Perigo extemo \\
\hline A11 & Técnico de inspecção da ficha & B9 & Temenos de fundaçäo \\
\hline c & Mecanismos de colapso (C1-C7) & D & Reparagôes e custos (D1-D5) \\
\hline C1 & Mecanismos de colapso estrutural & & \\
\hline $\mathrm{C} 2$ & Nivel de actuaçăo em relação ao colapso & D1 & Dano de ordem decorativa e em obras de arte \\
\hline C3 & İndice de dano & D2 & Breve descriçăo e estimativa do valor das obras \\
\hline$C 4$ & Condip̧ôes de operacionalidade e utilizaçăo do & \multicolumn{2}{|c|}{ necessárias } \\
\hline edficio & & D3 & Documentação uôlizada \\
\hline $\begin{array}{l}\text { C5 } \\
\text { pessoas }\end{array}$ & $\begin{array}{l}\text { Unidades imobiliánas inabitáveis, familias e } \\
\text { evacuadas }\end{array}$ & \multicolumn{2}{|c|}{$\begin{array}{l}\text { U4 Comentario final relatvo ao estado do editicio e } \\
\text { potencial utilizaçăio ou reocupaçăo }\end{array}$} \\
\hline C6 & Rigor da inspecção e registo & D5 & Equipa que realizou o levartamento \\
\hline c7 & Observapöes importantes & & \\
\hline
\end{tabular}

Fig. 9 - Estrutura da Ficha de Levantamento Exaustivo de dano em edifícios correntes - Modelo B.

$\mathrm{Na}$ terceira secção deste modelo são identificados os vários mecanismos de colapso presentes no edifício, (fig.10), estes mecanismos vão ser importantes na quantificação do índice de dano.

Posteriormente o índice de dano vai interferir na estimativa do dano presente no edifício, que é calculado na quarta secção deste modelo. Por fim o perito responsável elabora um comentário final acerca do estado do edifício, das medidas de emergência a tomar, identificando se o edifício se encontra ou não em condições de utilização. 
territorium 20

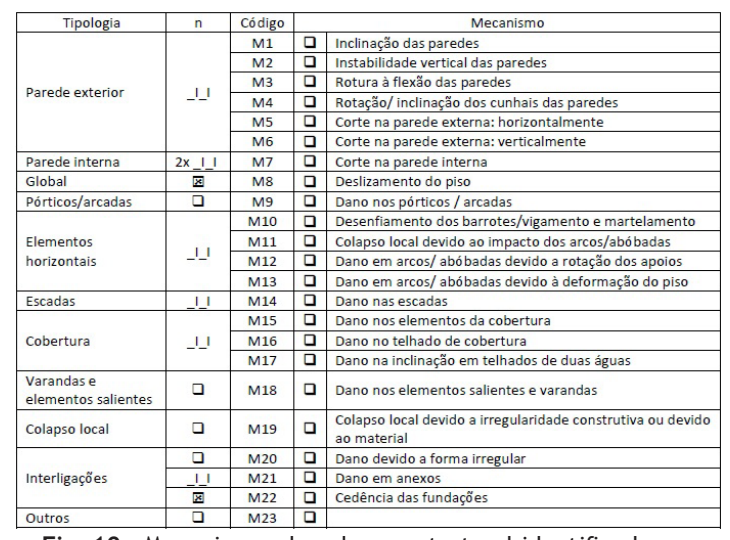

Fig. 10 - Mecanismos de colapso estrutural identificados no Modelo B.

\section{Conclusão}

Como se constata, há países mais propícios ao acontecimento de desastres naturais. Isto deve-se essencialmente, não só à sua localização geográfica, mas também a outros factores. Por outro lado, países com maior número de habitantes são os que estão sujeitos a maior número de vítimas. O desenvolvimento das grandes cidades deixa os habitantes vulneráveis a estes fenómenos impossíveis de evitar.

Entre os vários tipos de desastres possíveis, os desastres geofísicos são os mais destrutivos, os que provocam maior número de vítimas e mais danos/prejuízos de ordem económica. Alguns marcam para sempre a história de um país, pois demoram anos ou mesmo décadas para se voltarem a erguer. A zona mais fustigada com este tipo de fenómenos encontra-se localizada no anel de fogo do pacífico.

O principal objectivo de toda a humanidade, passa pela prevenção e previsão da ocorrência de fenómenos sísmicos, uma vez que são fenómenos impossíveis de evitar. A criação de cenários de actividade sísmica é também importante uma ferramenta na avaliação destes fenómenos. Por todo o Mundo são criadas diversas campanhas e estratégias para fazer face a estes acontecimentos, todas diferentes e com várias ideias, mas com um único fundamento: evitar que aconteça o pior.

Após um evento sísmico, é preciso agir rapidamente, de forma organizada e controlada. Uma resposta eficiente é fundamental para poder voltar tudo à normalidade no mais curto espaço de tempo. Problemas como a propagação de epidemias, a falta de água e comida e bens essenciais no dia-a-dia, a segurança dos habitantes, entre outros, são as principais preocupações das entidades envolvidas. A eficácia de uma boa gestão póssismo está directamente relacionada com a prevenção e mitigação antes da ocorrência de um evento sísmico.

Estas fichas de levantamento de dano são relativamente rápidas de preencher e bastante intuitivas de usar, sendo estas características essenciais durante o período de emergência sísmica.

O diagnóstico baseado no levantamento pode ser transformado em medidas para o restauro e melhoramento sísmico das estruturas, sendo para isso necessário ainda proceder ao estudo aprofundado dos mecanismos de dano que afectam as estruturas.

\section{Referências bibliográficas}

ABASSI, L. (2010) - Destruição nas proximidades de Portau-Prince. Haiti. http://www.boston.com/ bigpicture/2010/01/haiti_48_hours_later.html. (Site consultado em 10 Maio 2011).

AEDes (2000) - Scheda di $1^{\circ}$ Livello di Rilevamento danno, pronto intervento e agibilità per edifici ordinari nell'emergenza post-sismica. Itália.

Alexander, D. (2002) - Long- term Planning: Principles of Emergency Planning Management. England.

Azevedo, J. (2008) - “Caracterização da Acção Sísmica”. In Orion, E. Sismos e Edifícios. Capítulo 4. pp. 147-161

Baggio, C.; Bernardini, A.; Colozza, R.; Corazza, L.; Bella, M .D.; Pasquale, G. D.; Dolce, M.; Goretti, A.; Martinelli, A.; Orsini, G.; Papa, F.; Zuccaro, G. (2000) - Manuale per la compilazione della scheda di $1^{\circ}$ livello di rilevamento danno, pronto intervento e agibilità per edifici ordinari nell'emergenza post-sismica. Roma.

Beer, T.; Bonrowsky, P; Canuti, P; Cutter, S e Marsh, S (2007) - Desastres Naturais, Minimizar o risco, maximizar a Consciencialização,vol3.

Burnie, D. (2004) - Endangered Planet. In Mclean, R. Biblioteca do Conhecimento Juvenil. Rio de Mouro. Kingfisher Publications. Capítulo 2. pp. 28-29

Cansado, E. C. (2001). - "Mitigação do Risco Sísmico em Portugal. O papel do LNEC". In Spes; Gecorpa. Redução da Vulnerabilidade Sísmica do Edificado. Lisboa, Portugal. Capítulo 2. pp. 57-67

Claessens, M. (2008) - "Preparing for a storm". Reserch'eu, Revista del Espacio Europeo de la Investigación. No 8, October 2008

ERDIK, M. (1996) - Seismic Risk Analysis for Urban Systems. 11 WCEE. Macedónia.

KobaYASHI, M. (2004) - Seismic Destruction. http:// environment.nationalgeographic.com/ environment/natural-disasters/earthquakeprofile/. (Site consultado em 12 Fevereiro 2011). 
BANCO MUNDIAL (2011) - Banco Mundial, Indicadores do Desenvolvimento Mundial. http:// www.google.com/publicdata/ explore?ds=wb-wdi\&met $=$ ny_gdp_mktp_ cd\&idim=country:PRT\&dl=pt-PT\&hl=pt - PT\& $q=$ pib\#! ctype $=$ \&strail=false\&bcs $=$ d\&nselm $=$ h\&met_y=sp_pop_tot $\&$ scale_y=lin\&ind_y= false\&rdim=country\&idim= country: $\mathrm{CHN}$ :ES P:ITA:IND:BRA:FRA:PRT\&ifdim=country\&hl= pt_PT\&dl=pt_PT\&ind=false. (Site consultado em 15 Junho 2011)

Oliveira, C. S.; Roca, A.; Goula, X. (2006) - "Assessing and Managing Risk. An introduction". In SPRINGER. Assessing and Managing Earthquake Risk. Lisboa, Portugal. Capítulo 1. pp. 1-25

Oliveira, C. S. (2008) - "Efeitos Naturais, Impacte e Mitigação". In ORION, E. Sismos e Edifícios. Capítulo 3. pp. 59-127.
PC. (2006) - Scheda per il rilievo del danno ai Beni Culturali - Palazzi, modelo B- DP, de Emergenza post-sisma. Itália.

SCAWTHORN, C. (2003) - "Earthquakes: A Historical Perspective”. In Press, C. Earthquake Engineering Handbook. Berkeley, CA. Capítulo 1. pp. $12-33$

Vicente, R.; Silva, J. M. D.; Varum, H.; Costa, A. (2010) Caderno de apoio à avaliação do risco sísmico e de incêndio nos núcleos urbanos antigos do Seixal. Seixal.

Vicente, R.; Silva, J. M. D.; Varum, H.; Costa, A. (2010) Risco Sísmico e de Incêndio nos Núcleos Urbanos Antigos do Seixal. Seixal.

Zêzere, J. L.; Pereira, A. R.; Morgado, P. (2007) - Perigos Naturais e Tecnológicos no território de Portugal Continental. vol 12. 